\title{
Does Azerbaijani social media use data analysis as news?
}

\section{Vafa Zahid Isgandarova ${ }^{1}$}

1. PhD in Philology at Baku State University, Faculty of Journalism, Department of International Journalism, Baku, AZERBAIJAN, E-mail: vafa1.aslan@gmail.com

\begin{abstract}
The article is about new area of media - data driven journalism which spread in all over the world widely. Here is researched the Azerbaijani internet media outlets activity, some challenges and progress, made survey related to audience's interest about that. Social media, a branch of the Internet, is less used in data journalism because it is more operative and concise. Because it takes time to collect the data, visualize it and turn it into a story. Irrespective of that, Azerbaijani social media outlets such as Modern.az, Qafqaz.info, Report.az, BBC Azerbaycanca, Sputnik.az, Telegraph.com and etc. make a great effort to use data driven journalism trend. The majority of them are made by an editorial department to create info graphics, pie chart, and other visualizations tools.
\end{abstract}

Keywords: Data, Social Media, Visualization, Internet, Analysis, News, Information, Production, Process

\section{INTRODUCTION}

The new area of media- data analysis is an increased interest in journalism, since this is the one which will eventually implement any changes being considered. Data journalism is a journalism specialty that reflects the use of digital data in the production- digitization and distribution- visualization of information. After visualization the journalists is able to create a story. More profoundly the journalist's responsibility is to find data by using data machines such as social plat- forms, statistical offices, NGO or governments' bases, then analyze it, making it visible and to finalize it (data, filter, visualize, story) as a story according to profile of media outlets. This area highlights the increasing role of interaction between content producers and other industries, for example design, informatics and statistics. From the perspective of journalists, this is a set of advantages that come from various fields. Data journalism is used to combine a number of concepts and their relationships with journalism. Sometimes it is viewed as different levels or stages of new technologies going 
from simple to complex in the process of information production, processing and distribution. In fact, data journalism is an extremely tough area that involves the large-scale digital information that is now available through software. The majority of well-known media outlets like Guardian, Financial Times, The New York Times, Wall Street Journal, Independent, Die Zeit, Washington Post, USA Today, Bloomberg, Sputnik, Dag Media etc. utilize data journalism in a broad way. But this is a new and unexplored area in terms of science and education in Azerbaijan; also the journalists almost have very little use of data on social media. The only source of Data Journalism in Azerbaijani language is "The Data Journalism Handbook" by J. Gray, L. Bounegru and L. Chambers translated into Azerbaijani by Karim Aliyev from Mingachevir State University. And there is only one article called Data journalism written by Aynur Bashirli, Khanim Javadova, Sabina Izzatli in the book New Media Journalism published by Council of Europe within Programmatic Cooperation Framework for Azerbaijan, Armenia, Georgia, Republic of Moldova, Ukraine, and Belarus.

There is unique web site called www.eslinde.com created by Emin Huseynzade in Azerbaijan, which spreads only data information. But the last update writing of this site was realized on February 13, 2019. Azerbaijani social media outlets almost do not use info graphics on their pages. Some of them rarely use info graphics. The present article tries to find the major reasons of this insufficiency and future strategies related to enhancing of this sphere in Azerbaijan.

\section{THEORETICAL BASEMENT AND LIT- ERATURE REVIEW}

Today, the context and scope of data-driven journalism have expanded considerably from its evolutionary antecedent, following the explosion of data generated in and about nearly every aspect of society, from government, to industry, to research, to social media (Howard, 2017: 8). Data journalism has come a long way since it reached its current state. First of all at the beginning of XXI century scientists started thinking of journalism as programming and the term "informational journalism" was the creation of news by focusing on information. "Many researchers have been deprived of data journalism as "journalistic journalism", "journalism journalism", “journalism programming", "journalism programming", and "news programs". These notions indicated that information journalism differs from traditional journalism but follows the procedures for creating news stories" (Oliver, Florian, 2018: 2-3). At a later milestone, the true essence of data journalism began to emerge. There were various new terms which explained this theory more precisely:

"CAR (computer assisted reporting)", "data driven journalism", "data based journalism", "open source traffic", "precisive journalism", "quantitatively oriented journalism", "automatised journalism", "investigative journalism", "computational journalism, "digital journalism", "data driven journalism" and many more. Some researchers differentiated following terms with each other for instance, computational journalism (Karlsen and Stavelin), programmer-journalism (Parasie and Dagiral), open-source journalism (Lewis and Usher), or data journalism (Appelgren and Nygre; Fink and Schudson; Gynnild ) etc. But the theoretical core of these notions is the samedata driven. "The Latin etymology of 'data' means 'something given,' and though we've largely forgotten that original definition, it's helpful to think about data not as facts per se, but as 'givens' that can be used to construct a variety of different arguments and conclusions; they act as a rhetorical basis, a premise," wrote Nick Diakopoulos. But data does not intrinsically imply truth. Yes, we can find truth in data, through a process of honest inference, but we can also find and argue multiple truths or even outright falsehoods from data (Howard, 2017:19).

From these points of views, scientists have designated data journalism as an experience that uses automated reporting and accurate journalistic-based visualization, news application, and discovery of data. Data journalism is an integrative practice that integrates deep research into Lim 3 statistics, graphic design and programming (Nathalie, Christophe, Nicholas, Sheelagh, 2018: 158). As a phenomenon of the up-todate world, data journalism has came to the stage by the demand of investigations, statistical and number based information. Therefore, data is an integral part of investigative journalism. In order to produce a qualitative data, a journalist should be able to use software to get a huge opportunity to understand and work on data using modern technology.

"There are three main types of data news: 1. Datadriven news - which is the news directly made on the base of the given data. 2. The News data for investigations - which are not directly news on given data, but the explanation, clarity or investigation of used data for news here. 3. The news that explains data - here the news shows the way that brings to the data. This is for making the pathway easy to readers by journalists" (Gray, Bounegru and Chambers 2012: 191). 
In a word, the journalist first collects data sources from agencies that have data through search engines (Csv, xls, pdf files, indexed databases etc.), then filters them with various programs such as Spreadsheet, Google Spreadsheets, Microsoft Excel, Google Refine, Data Wrangler, Comet Docs, Mr. Data Converter), after then visualizes the finished material through graphic programs (Tableau Public, Many eyes Color Brewer, D3.js, Fusion Charts, Fusion Tables, Fusion Tables Layer Wizard, Gephi, Google Charts, Google Maps Style Wizard, High Charts, SHP Escape) and adds a story to the audience.

There are innumerable publications in this field in many different languages around the world. "The Data Journalism Handbook" consisted of two books written by J. Gray, L.Bounegru and L.Chambers are the most widespread theoretical source for journalists and researchers. One of the vital sources is "Ethics for digital journalism" edited by Lawrie Zion and David Graig includes in the best explanations about data journalism by P.Bradshaw. The main trends and streams in data journalism have been scrutinized by Turo I Uskali, Heikki Kuutti and Tanja Aitamurto, Esa Sirkkunen, Pauliina Lehtonen from Finland University. Ester Appelgren and Gunnar Nigren which are considered to be the first to use the term data journalism are famous researchers in this area in Sweden. The majority of specialized research centers and universities (School of Data, Tow Center for Digital Journalism, Columbia University, Massachusetts University, Texas University, VCU) regarding to data journalism are mainly in USA and Great Britain. Katherine Fink, C.W.Anderson, Mark Coddington, Baranetsky, D. Victoria, Howard Alexander Benjamin, King George, Alessandro Martinisi, Jeff South, and many more researchers have been conducting researches in this area for a long time. Publications such as Journalism Studies, Digital Journalism, Journalism Practice etc. supported by Taylor and Francis group regularly publish articles on the subject we are researching.

Seth C.Lewis from USA and Oscar Westland from Sweden have written epistemology about big data and journalism, also given economics and ethics of this issue. Carl V. Lewis from Mercer University researches tools and resources of data journalism. Eddy-Borges-Rey and Megan Knight study data journalism practice in British newsrooms nowadays. Juliette De Maeyer, François Heinderyckx, Florence Le Cam, Manon Libert and David Domingo are French-speaking Belgium scientists; they have given a quantitative assessment of the anecdotal take-up of data journalism in Belgium. Among the important literature on data journalism, the guide Data Literacy by David Herzog deserves special mention. Assuming the reader has no advanced knowledge of data analysis or statistics, this book shows how to create insight from publicly-available data through exercises using simple Excel functions. Extensively illustrated, step-by-step instructions within a concise, yet comprehensive, reference will help readers identify, obtain, evaluate, clean, analyze and visualize data (Herzog, 2016). Investigative Reporter's Handbook is a guide to documents, databases, and techniques by Brant Houston Bedford/St. Martin`s published with investigative reporters and editors, Inc. (IRE) is about how to use fundamental news reporting and writing skills, from gathering sources to tracking information (Investigative Reporter's Handbook, 2008). A survival guide "Investigative journalism" by David Leigh also gives vast information legal bullies, crooked politicians, media bosses, big business and intelligence agencies; how to withstand conspiracy theories; and how to work collaboratively across borders in the new age of data journalism (Leigh, 2019).

Irina Radchenko and Anna Sakoyan are the co-founders of open educational source data driven journalism.ru in Russia and its data expeditions are an example of an attempt to adopt this approach. One of the world's leading scientists in this field from Turkey Pinar Dag`s background is related to data journalism in terms of tuition it in Kadır Has University and practice on her web site Dag Media, which spreads data news frequently.

Certain paradoxes seen in Azerbaijan encouraged us to ask the main question of whether need data information on social media. On the one hand up-to-date world as well as modern society is in search of frequently updated news. And it takes a long time to turn this news into digital or video info graphics. Therefore, most Azerbaijani social media platforms do not need data analysis materials. On the other hand, it is easier and more curious for a 21st century person to perceive info graphic information. According to the editor of Eslinde.com Emin Huseynov, the big problem related to Azerbaijani data journalism is access to databases. According to him, the next problem is that editors do not allocate funds in this area and do not support journalists in realizing their individual aspirations in this area. Also Azerbaijani audience still does not fully trust in the data information (Ekinchi media, 26 May 2020).

\section{METHODS AND ANALYSIS}

In this article has been monitored the 2019-2020 online editions of a number of well-known websites and 
media outlets such as - AzerTac, Modern.az, Qafqaz. info, Report.az, Telegraf.com, BBC Azerbaijan, Sputnik.az, and Inter.az operating in Azerbaijan in connection with the issue under investigation. Here has used content analysis of data information in question sites and the Likert scale survey type as a methodology. Simultaneously, we have interviewed the editors of Report.az, Modern.az and Telegraf.com, also Dean of the Journalism Faculty of BSU Vugar Aliyev and learned their views on the need for and future status of data journalism.

The largest news agency AzerTac, emphasized in its 100th anniversary issue that our site produces info graphics, slideshows, video graphics, 360 videos. However, we did not find any data in the editions we reviewed. There were info graphics provided by the Anatolian Agency only on certain significant days. Modern.az platform has recently provided digital information on the current situation with COVID-19, according to organizations WHO's and Medical Territorial Units Management Association`s (Azerbaijan) info. However, none of this information was visualized. Site`s editor Afgan Gafarli mentioned, that digital information is very important, but our journalists do not have digital knowledge and analytical skills. This is a common problem for the Azerbaijani media sector. In this regard, journalists should be involved in practical training. We will pay more attention to this area in the future. Qafqaz.info site does not have the digital information it visualizes as well. Only info graphics prepared by a number of agencies and media outlets, such as the Statistics Office, Azercell Telecom MMC, the Center for Economic Reform Analysis and Communication, and the Russian Arguments and Facts newspaper, was used. News site Inter.az benefits info graphics with different content taken from Russian Arguments and Facts newspaper and Salam news agency as well. BBC Azerbaijan site has prepared their own data graphics about president's activity, his meetings and relationships with international organizations, official visits, generally, his activity by months, but very rarely throughout 2016 year. In the previous years the site have utilized Tom Keatinge, Brookings Institute, Sysomos Analitics`s info graphics about religion Islam and various terrorist organizations. More recently, the site has benefited from important figures of BBC World Service and Johns Hopkins University regarding to coronavirus. The features of data journalism have been used a little more extensively by Report. az information agency. For the periods under study, digital information prepared by the agency itself on e-cash registers, application of tax benefits, prices of goods in various markets, construction sector, SO-
CAR loans, and bank credit rates' was presented. However, the info graphics presented by Report.az are very simple and are not based on in-depth research. According to editor of this agency Parvin Abbasov, as a news agency, they prefer national and global short stories for all over the world. The reason for the lack of digital information is that we are focused on daily news. He noted that if the number of employees increases in the future, we expect this information to enlarge. The chief editor of the "Telegraph.com" Nargiz Javadzade also emphasized that, this shortcoming is due to the economic stagnation. Sputnik.az is the leading online platform that benefits the most from data journalism among monitored Azerbaijani social media outlets. The site always provides quite informative and colorful info graphics related to political, economic, socio-cultural events. Statistical information from sources such as www.stat.gov.az, www.social.gov. az, www.unicef.org, www.country-meters.info, www. worldmeters.info, www.who.int was visualized by Editors Ulker Abdullayeva, Emin Aliyev, Tahir Balayev and designer Elnur Salayev.

We have conducted an online survey via Survey Monkey to answer the questions posed above. According to survey, not all respondents do prefer data journalism completely. The majority of them partially trust on data information of Azerbaijani social media outlets. Thus, 33, $33 \%$ of the respondents do trust the BBC Azerbaijan the most among the sites we surveyed, followed by Qafqaz.info and Modern.az. 10\% of respondents said they trust AzerTac and Report.az. Respondents said they do not rely entirely on Sputnik.az and Telegraf.com websites.

Despite of that, among them Sputnik.az pays more attention to data news and their visualization.

Approximately 66.67 percent of respondents wanted to visualize data news. Generally $45.5 \%$ of the Azerbaijani audience surveyed rely more on local sites in the Internet media, $36.6 \%$ trust foreign sites, and $18.8 \%$ do not trust any of them. Due to respondents ' answers the majority of them do not want to switch to data news on social media altogether.

\section{CONCLUSION}

To sum up, we can conclude that, although data analysis is a very important trend in journalism nowadays, Azerbaijani social media outlets rarely take advantage of it. A large part of the Azerbaijani audience partially trusts on data information of Azerbaijani social media outlets. Among them Sputnik.az, BBC Azerbaijan and Report.az sites provide some data information. Oth- 
Graph 1: The Percentage of Readers Watching the Media According to the Reliability of The Data News

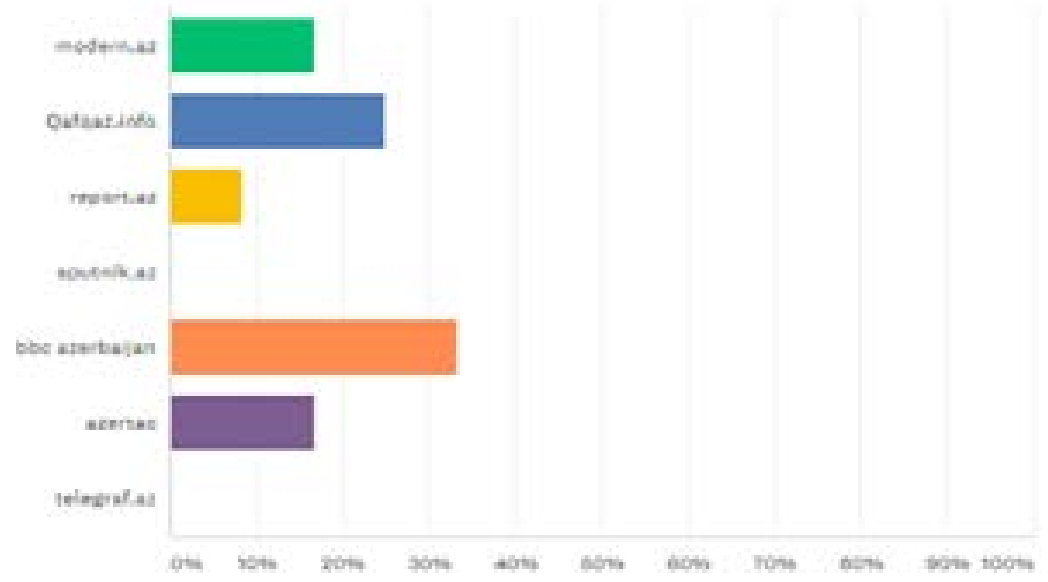

Source:: https://www.surveymonkey.com/analyze/

Q4dohGz 2F9VyherQkJNLMSeLfq4k0twiMpQGXBTPC 2FULFf45FqKeahWGM6EOHsquK

Graph 2: Percentage of Readers Who Need the Visualization of Data News

\section{Do you need visualization of data news?}

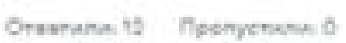

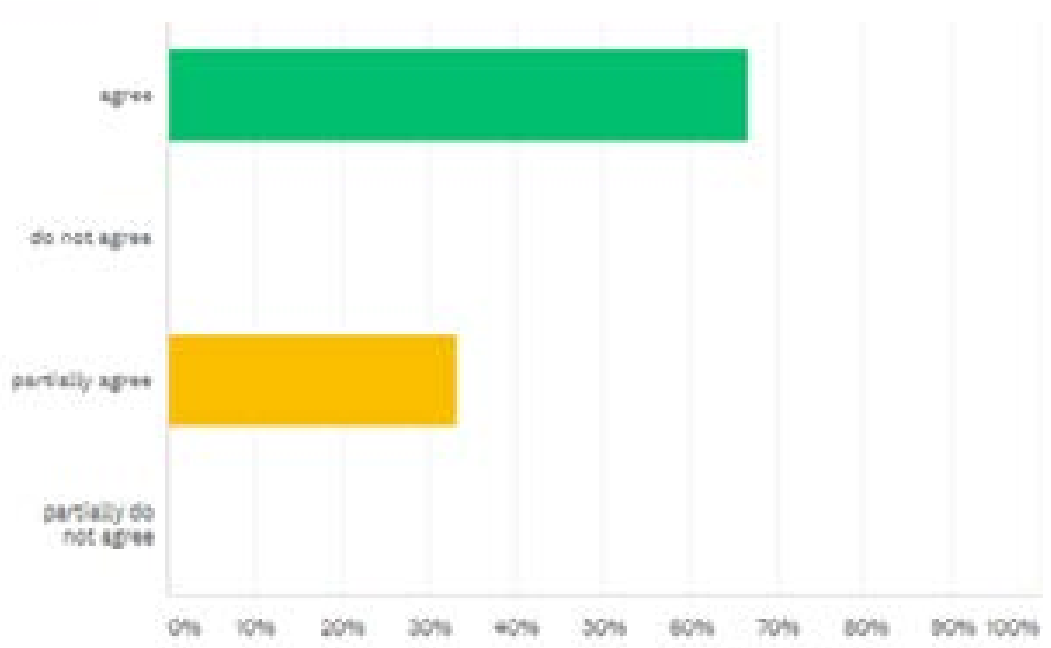

\begin{tabular}{|c|c|c|}
\hline 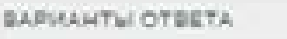 & - orestial & $*$ \\
\hline - do nus ages & $0,00 \%$ & $\theta$ \\
\hline - earsially ages & $23,23 \&$ & 4 \\
\hline - pursially do net agres & $0,00 \leqslant$ & $\theta$ \\
\hline
\end{tabular}


Graph 3: Confidence of Azerbaijani Readers in The Reliability of Data on Social Media

\section{Do you trust data news on social media?}

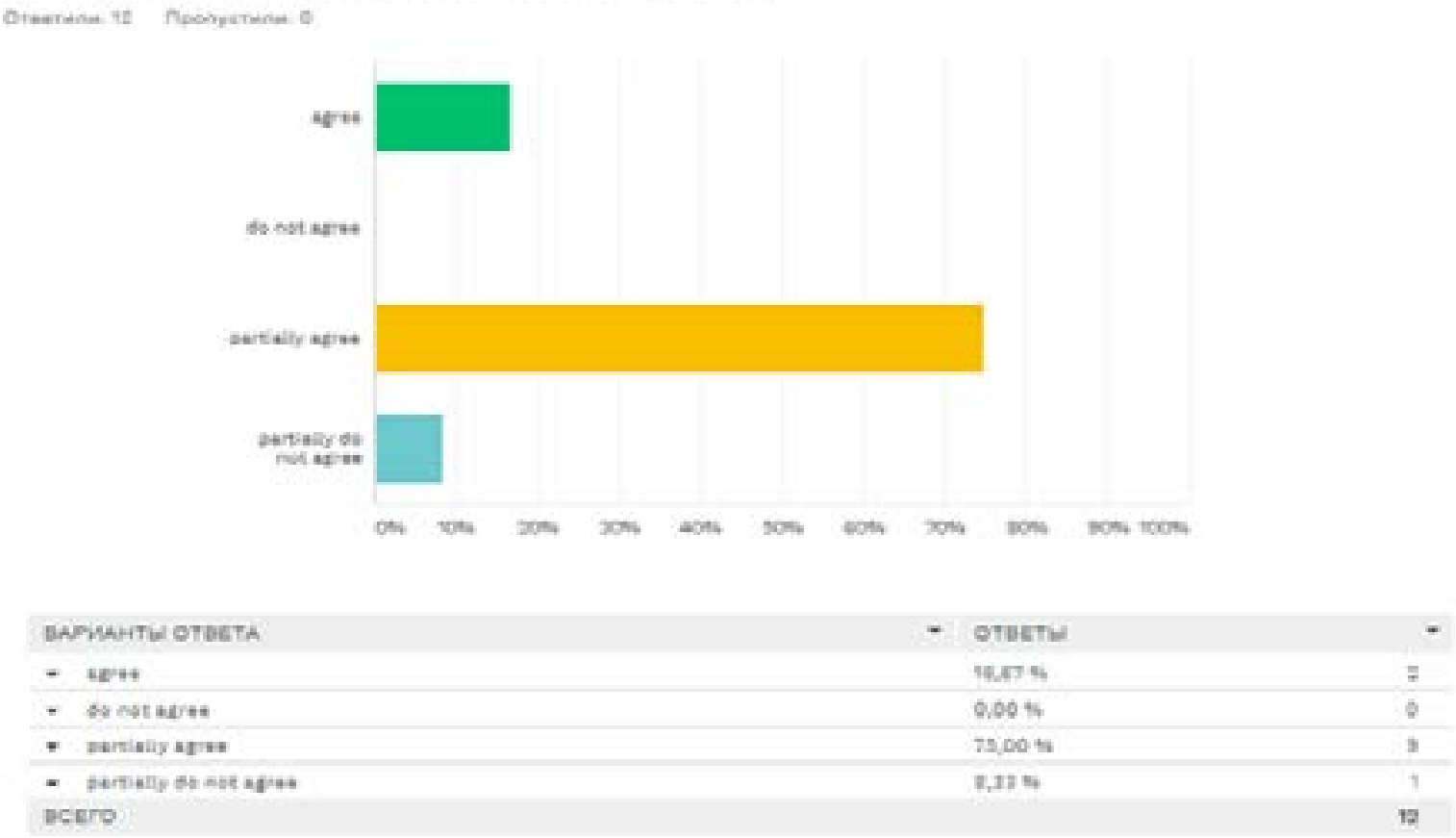

er sites involved in the study almost do not utilize it. They benefit foreign media outlets' data information more. This is due to lack of funds and professional staff in this area. Media schools and institutions in Azerbaijan do not specialize in data journalism as well. There is no serious theoretical basis, research work or textbook in the Azerbaijani language in this sphere except for Karim Aliyev's translation book. However, the interviewing editors expressed positive views on the development of data journalism in the near future. Dean of the Faculty of Journalism of BSU Vugar Aliyev also said that, data journalism is still a nascent concept in the emerging hyper local media sector and new specialties related to the training of data journalists will be acquired. And in the future it is expected to prepare theoretical literatures in this area. In a word steps taken in Azerbaijani media sector can be making it more mainstream.

\section{REFERENCES}

- BəŞİRLİ , A., \& CAVADOVA, X. \& İZZəTLİ, S. (2017). Yeni Media Jurnalistikası. Bakı: Avropa Şurası. 66.

- OLIYEV, K. (2018). Data Journalism Handbook. Mingəçevir: Mingəçevir Dövlət Universiteti.

- GRAY, J., \& BOUNEGROU, L. \& CHAMBERS, L. (2012). The Data Journalism Handbook, How journalists can use data improve the news, O'Reilly.

- HOWARD, A.B. (2017). The art and science of datadriven journalism, Tow Center for Digital Journalism, 144 p. https://academiccommons.columbia.edu/ doi/10.7916/D8Q531V1

- HERZOG, D. (2020). Data literacy. Sage Publication, İnc. Took from the address https://www.amazon. com/Data-Literacy-David-Herzog/dp/1483333469 (Access date: 15.01.2020)

- OliVER, H. \& FLORIAN, S. (2018). Digital Investigative Journalism: Data, Visual Analytics and Innovative Methodologies in International Reporting. Basingstoke: Palgrave Macmillan; $1^{\text {st }}$ edition.

- NATHALIE, H., \& CHRISTOPHE, H., \& NICHOLAS, D., \& SHEELAGH, C. (201). Data-Driven Storytelling. Massachusetts A K Peters/CRC Press; $1^{\text {st }}$ edition. 
- Investigative Reporter's Handbook: A Guide to Documents, Databases, and Techniques. Took from the address https://issuu.com/fashionbag444/ docs/0312589972-investigative-reporters-handbookby-brant-houston (Access date: 10.11.2020)

- Investigative journalism. A survival guide. https:// www.palgrave.com/gp/book/9783030167516 (Access date: 7.10.2020)

- EKINCHI MEDIA, 26 May 2020, https://www. youtube.com/watch?v=0nn]hsxxdvU (Access date: 23.09.2020)

- URL 1. Open Data 500 Gov. Lab. http://www. opendata500.com/ (Access date: 3.09.2020)

- URL 2. Open Data Institute. Startups. http://theodi. org/start-ups (Access date: 11.11.20202)

- URL 3. https://academiccommons.columbia.edu/ doi/10.7916/D8Q531V (Access date: 8.12.2020)

- URL 4. https://www.tandfonline.com/ (Access date: 29.12.2020 ) 